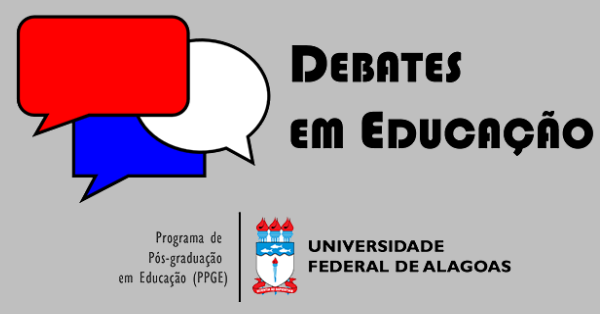

ISSN Eletrônico 2175-6600

Vol. 13 | No. 31 | Jan./Abr. | 2021

Karen Werlang Lunkes

(o) iD

Universidade Federal do Rio Grande do Sul

(UFRGS)

mk.lunkes@gmail.com

Fernanda Kerbes

9 iD

Prefeitura Municipal de Porto Alegre

fkerbes@gmail.com

Ana Sara Castaman

$\theta$ id

Instituto Federal de Educação, Ciência e Tecnologia do Rio Grande do Sul (IFRS) ana.castaman@sertao.ifrs.edu.br

\section{FORMAÇÃO CONTINUADA PARA PROFISSIONAIS DA EDUCAÇÃO DO SETOR PÚBLICO FEDERAL}

\section{RESUMO}

O estudo objetiva discutir a formação continuada dos profissionais da educação do setor público federal, a partir de conceitos e regulamentos que fundamentam esta temática. Caracteriza-se por abordagem qualitativa, do tipo bibliográfica e documental e está dividido em duas partes: a) a formação continuada dos profissionais da educação; b) desenvolvimento de pessoas no setor público, ampliando o debate para o papel da gestão na institucionalização de uma formação continuada para os profissionais da educação no setor público. Conclui-se que a formação continuada pode promover o desenvolvimento dos servidores públicos nas competências necessárias à consecução da excelência na atuação dos órgãos e das entidades da administração pública federal direta, autárquica e fundacional.

Palavras-chave: Formação continuada. Profissionais da educação. Servidor público.

\section{CONTINUING EDUCATION FOR EDUCATION PROFESSIONALS IN THE FEDERAL PUBLIC SECTOR}

\section{ABSTRACT}

The study aims to discuss the continuing education of education professionals in the federal public sector, based on concepts and regulations that support this theme. It is characterized by a qualitative approach, of a bibliographic and documentary type, and is divided into two parts: a) continuing education of education professionals; and b) development of people in the public sector, expanding the debate on the role of management in the institutionalization of continuing education for education professionals in the public sector. It is concluded that continuing education can promote the development of public servants in the competencies necessary to achieve excellence in the performance of the agencies of the direct, autarchic and foundational federal public administration.

Keywords: Continuing education. Education professionals. Public server.

Submetido em: 09/03/2021

Aceito em: 08/05/2021

Publicado em: 26/06/2021

https://doi.org/10.28998/2175-6600.2021v13n31p1132-1153 


\section{INTRODUÇÃO}

À gestão pública compete coordenar e executar as políticas públicas, definindo a distribuição e o cumprimento da autoridade política e o atendimento aos interesses públicos. Essas funções concretizam-se por meio de atitudes, normas, processos e instituições (OLIVEIRA, 2008). Vinculados ao Ministério da Educação (MEC), as Instituições Federais de Ensino Superior (IFES) e a Rede Federal de Educação Profissional, Científica e Tecnológica (RFEPCT) são mantidas pela União e integram a complexa Rede Federal de Ensino (BRASIL, 1996). De acordo com o Portal do MEC (BRASIL, 2021), em 2019, a Rede Federal era composta por 42 instituições, sendo 38 Institutos Federais de Educação, Ciência e Tecnologia (IF), 02 Centros Federais de Educação Tecnológica (CEFET), a Universidade Tecnológica Federal do Paraná (UTFPR), o Colégio Pedro II, além de 22 escolas técnicas vinculadas às universidades federais. Entre as IFES, existem atualmente 68 universidades federais (ANDIFES, 2021). Tais instituições desempenham papel central no desenvolvimento científico e tecnológico do país, respondendo por cerca de $90 \%$ da produção científica brasileira e pela formação de profissionais nas mais diversas áreas do conhecimento (MENEZES; SANTOS, 2001).

As Instituições Federais de Ensino (IFE) são compostas por servidores públicos "devidamente organizados e regulamentados por regimento que tem por objetivo executar leis e objetivar as políticas governamentais" (CURY, 2000, p. 105), os quais dividem-se em três categorias diferentes: docente do ensino superior; docente do ensino básico, técnico e tecnológico e técnico-administrativo em educação. Além das particularidades previstas em suas próprias carreiras, de forma geral, todos estão submetidos ao Plano Nacional de Desenvolvimento de Pessoal (PNDP), atualizado pelo Decreto $\mathrm{n}^{\circ} 9.991$ (BRASIL, 2019a), cuja finalidade é a de promover o desenvolvimento dos servidores públicos nas competências necessárias à consecução da excelência na atuação dos órgãos e das entidades da administração pública federal direta, autárquica e fundacional.

Logo, para consolidar a função das IFEs é preciso a "valorização do profissional da educação escolar" (BRASIL, 1996), promovendo o desenvolvimento de seus servidores, uma vez que as pessoas que compõem as instituições de ensino são seu maior patrimônio (CASTAMAN; RODRIGUES, 2018). Nesse sentido, o presente estudo considera como profissionais da educação tanto os técnico-administrativos em educação quanto os docentes que integram o quadro de pessoal das IFEs. Assim, almeja-se uma formação continuada que atenda não somente à atualização, à qualificação da profissionalização e à identificação de soluções para os problemas concretos da 
educação, mas à própria natureza das práticas educativas, enquanto um constante vir a ser e, sobretudo, que considere os profissionais da educação enquanto sujeitos ativos de seu desenvolvimento, de suas experiências no exercício da profissão e nas suas histórias de vida. "Urge por isso (re)encontrar espaços de interação entre as dimensões pessoais e profissionais, permitindo aos professores apropriar-se dos seus processos de formação e dar-Ihes um sentido no quadro das suas histórias de vida" (NÓVOA, 1995, p. 25), (Sic), entendendo-se, neste contexto, todos os profissionais da educação, incluindo o quadro técnico.

Dessa maneira, objetiva-se discutir a formação continuada dos profissionais da educação do setor público federal ${ }^{1}$, a partir de conceitos e regulamentos que fundamentam esta temática. Sob este aspecto, apresentam-se as diretrizes definidas em lei para o desenvolvimento desses profissionais, de forma alinhada ao PNDP. Para essa finalidade, o estudo caracteriza-se por abordagem qualitativa, do tipo bibliográfica, para abordar as concepções da formação continuada e do desenvolvimento dos profissionais da educação. Ainda, trata-se de uma pesquisa documental, pois discorre sobre os principais regulamentos nacionais que embasam o desenvolvimento dos profissionais da educação na esfera federal.

Assim, este texto está dividido em duas (02) partes: a) trata da formação continuada e do desenvolvimento dos profissionais da educação; e b) aborda o desenvolvimento de pessoas no setor público, bem como discute o papel da gestão na institucionalização de uma formação continuada para os profissionais da educação no setor público.

\section{METODOLOGIA}

Metodologicamente, esta produção textual constitui-se enquanto abordagem, como qualitativa, uma vez que se utiliza de materiais empíricos, tais como textos e documentos (ASSIS GUERRA, 2014). Minayo (2007) salienta que a pesquisa qualitativa abarca um universo de significados, motivos, aspirações, crenças, valores e atitudes, possibilitando correlacionar relações, processos e fenômenos que não podem ser reduzidos à operacionalização de variáveis.

\footnotetext{
${ }^{1}$ Ressalta-se que grande parte dos conceitos de formação continuada para profissionais da educação foram adaptados, uma vez que a maior parte das publicações restringem-se à formação continuada apenas do docente.
} 
De acordo com os objetivos, caracteriza-se como exploratória, pois permite maior familiaridade com o problema, de maneira a torná-lo mais explícito ou a construir hipóteses. A maior parte dessas pesquisas remete a: (a) levantamento bibliográfico; (b) entrevistas com pessoas que tiveram experiências práticas com o problema pesquisado; (c) análise de exemplos que estimulem a compreensão (GIL, 2007).

Portanto, enquanto técnica, pauta-se em um estudo do tipo bibliográfico narrativo desenvolvido com base em material já elaborado, composto, principalmente, de livros e artigos científicos (GIL, 2008), bem como de análise pessoal crítica das autoras. Para leitura, descrição e análise das produções acerca da formação continuada, orienta-se em Marcelo García (1995, 1999), Marin (1995), Nóvoa (1995, 2002), Candau (1997), Rivas et. al. (1997), Pimenta (2000), Libanio (2001), Alvorado-Prada, Freitas e Freitas (2010), Gatti, Barreto e André (2011), Silva (2011), Rossi e Hunger (2012), Castaman e Vieira (2013), Libâneo, Oliveira e Toschi (2017), Vieira J., Vieira M. e Belucar (2018), Fernandes (2018) e Silveira e Castaman (2020). Para discutir sobre o desenvolvimento dos profissionais da educação ancora-se em Ricupero (1994), Veiga (1995), Candau (1997), Rechziegel e Vanalle (2000), Ramos (2001), Chiavenato (2006), Libâneo (2008), Lück (2008), Lope e Costa (2014), Fernandes (2018), Serpa (2020) e Andrade (2021).

Ainda apóia-se na pesquisa documental, a partir da análise de conteúdo (BARDIN, 2004) com a finalidade de organizar os dados fundamentada nas categorias identificadas no material coletado. Bardin (2004) ressalta que esse tipo de estudo pressupõe três (03) etapas, a saber: pré-análise, exploração do material e tratamento dos dados e da interpretação. A etapa inicial sugere o primeiro contato com o material: a seleção do que será utilizado; a formulação de hipóteses; a finalidade e os indicadores que irão conduzir a análise. A segunda etapa fundamenta-se na implementação do planejado, definindo as categorias de análise. Por fim, a terceira etapa alude à "geração de inferências e dos resultados da investigação. Nesta última fase, suposições poderão ser confirmadas" (VERGARA, 2005, p. 18). Dessa maneira, analisam-se os documentos oficiais: Brasil (1988, 1996, 1998, 2005, 2006, 2009, 2010, 2014a, 2014b, 2016a, 2016b, 2017, 2018, 2019a, 2019b), por meio das categorias: formação continuada e desenvolvimento dos profissionais da educação do serviço público federal.

Alicerçados neste referencial, apresentam-se as ideias defendidas na literatura mobilizada e as suas contribuições para o campo no qual se inscrevem ou ao qual se endereçam. 


\section{A FORMAÇÃO CONTINUADA E O DESENVOLVIMENTO DOS PROFISSIONAIS DA EDUCAÇÃO}

A Lei de Diretrizes e Bases da Educação Nacional (LDB) (BRASIL, 1996), alterada pelas leis $n^{\circ} 12.014$ (BRASIL, 2009) e $n^{\circ} 13.415$ (BRASIL, 2017), assim caracteriza os profissionais da educação:

Art. 61. Consideram-se profissionais da educação escolar básica os que, nela estando em efetivo exercício e tendo sido formados em cursos reconhecidos, são: I - professores habilitados em nível médio ou superior para a docência na educação infantil e nos ensinos fundamental e médio;

II - trabalhadores em educação portadores de diploma de pedagogia, com habilitação em administração, planejamento, supervisão, inspeção e orientação educacional, bem como com títulos de mestrado ou doutorado nas mesmas áreas; (BRASIL, 1996).

III - trabalhadores em educação, portadores de diploma de curso técnico ou superior em área pedagógica ou afim (BRASIL, 2009).

IV - profissionais com notório saber reconhecido pelos respectivos sistemas de ensino, para ministrar conteúdos de áreas afins à sua formação ou experiência profissional, atestados por titulação específica ou prática de ensino em unidades educacionais da rede pública ou privada ou das corporações privadas em que tenham atuado, exclusivamente para atender ao inciso $V$ do caput do art. 36;

$\mathrm{V}$ - profissionais graduados que tenham feito complementação pedagógica, conforme disposto pelo Conselho Nacional de Educação (BRASIL, 2017).

Outrossim, o documento final da Conferência Nacional de Educação (CONAE) (BRASIL, 2010) emprega o termo profissionais da educação para se referir aos professores, especialistas, funcionários de apoio e técnico-administrativos que atuam nas instituições e sistemas de ensino. Os documentos finais subsequentes (BRASIL, 2014a, 2018) balizam os profissionais da educação à LDB, ampliando àqueles que atuam na educação superior e aos servidores técnico-administrativos e de apoio. "[...] Não são apenas os professores que educam. Todas as pessoas que trabalham na escola realizam ações educativas, [...]". (LIBÂNEO, OLIVEIRA e TOSCHI, 2017, p. 414).

Tendo em vista que os estudos sobre a formação continuada são, em sua maior parte, aplicados ao profissional docente (MARCELO GARCÍA, 1995, 1999, NÓVOA, 1995, 2002, PIMENTA, 2000), ressalta-se, neste estudo, a adoção dos conceitos a um contexto mais amplo, incluindo a todos os profissionais da educação (FERNANDES, 2018, SILVEIRA; CASTAMAN, 2020). Assim, encontra respaldo a possibilidade de se acolher a

\footnotetext{
${ }^{2}$ A Associação Nacional pela Formação dos Profissionais da Educação (ANFOPE) luta em defesa de políticas de formação e valorização profissional da educação que assegurem o reconhecimento social do magistério, seu profissionalismo e profissionalização. Ou seja, trata em especial, dos docentes. Para conhecer mais, ver informações em: http://www.anfope.org.br/.
} 
formação continuada como recurso pedagógico para outras classes profissionais: "[...] a formação continuada é considerada essencial a profissionais que trabalham com a mudança, construção, incertezas, exigindo flexibilidade e habilidade de lidar com o inédito na ação cotidiana" (CASTAMAN e VIEIRA, 2013, p. 08), realidade compartilhada por todos os agentes inseridos no campo da educação. Trata-se de um continuum que se estende por toda a vida profissional (MARCELO GARCÍA, 1995, 1999, MARIN, 1995, PIMENTA, 2000).

A formação continuada é definida como "[...] um processo permanente de aperfeiçoamento dos saberes necessários à atividade profissional, realizado após a formação inicial, com a finalidade de assegurar qualidade ao processo ensinoaprendizagem". (VIEIRA J; VIEIRA M. e BELUCAR, 2018, p. 101). A formação continuada constitui-se um recurso que apoia os profissionais da educação no processo de ensinoaprendizagem de seus estudantes, bem como de qualificação dos processos educacionais no intuito de angariar "[...] novos conhecimentos teórico-metodológicos para o desenvolvimento profissional e a transformação de suas práticas [...]" (ALVORADOPRADA; FREITAS; FREITAS, 2010, p. 374).

Nesse sentido, alude-se que "[...] é um processo heterogêneo sendo preciso considerar todas as variantes envolvidas, como as necessidades e as expectativas dos profissionais da educação em cada momento do exercício profissional". (ROSSI e HUNGER, 2012, p. 335-336). Assim, por formação continuada entende-se aquela desenvolvida a partir da atuação no mundo do trabalho, também denominada formação em serviço ou capacitação. A oferta de formação continuada pode se dar mediante "[...] palestras, seminários, oficinas, cursos rápidos ou longos”. (GATTI; BARRETO e ANDRÉ, 2011, p. 198).

Já Marcelo García (1999) defende o uso do termo desenvolvimento profissional docente de modo a ressaltar a dimensão da profissionalização do ensino, bem como a perspectiva de evolução, descolada do binômio inicial e continuada, demarcando formações distintas. Em paralelo, é possível traduzir o mesmo conceito à profissionalização de outras categorias profissionais atuantes na educação e que carecem de uma formação com a mesma perspectiva integradora.

Ainda, segundo García (1999), no desenvolvimento profissional é possível encontrar a marca da intencionalidade e do planejamento de um processo educativo que ocorre a longo prazo, a partir de diferentes oportunidades sistematizadas, a fim de promover mudanças. Portanto, a maior beneficiária do resultado de um desenvolvimento profissional construído em bases sólidas e dialógicas é a própria sociedade. 
As abordagens progressistas ${ }^{3}$ de educação atrelam a formação continuada e o desenvolvimento humano e profissional aos compromissos com a transformação da sociedade, em um esforço coletivo de (re)construção das relações interpessoais e da convivência (LIBANIO, 2001). A pedagogia progressista parte de uma análise crítica das realidades sociais, sustentando as finalidades sociopolíticas da educação (LIBÂNEO, 1990). Destarte, engaja-se com a mudança social e não se constitui somente enquanto uma atualização.

As ações de desenvolvimento propostas com base em uma formação continuada favorecem a atualização da identidade pessoal e profissional do sujeito por meio da promoção do autoconhecimento e do reconhecimento de seu papel sociocultural (FERNANDES, 2018). Diante disso, a formação continuada passa a ser referência para a elaboração de ações que oportunizem, além dos conhecimentos teóricos, reflexão sobre si mesmo, sua relação com o outro e o seu entorno.

"[...] O significado e as exigências da formação do profissional da educação supõem o entendimento do que seja profissão e do que seja a formação para e na atuação profissional". (RIVAS et. al.,1997, p. 139). Silva (2011) salienta que a natureza do trabalho desse profissional requer uma formação científica, artística, ética e técnica de elevado nível de:

[...] tarefas, portanto, de prática e teoria. Constrói-se, dessa maneira, o verdadeiro sentido da práxis como ação transformadora sustentada pelo conhecimento da realidade e reflexão, que pode superar o imobilismo e fortalecer o sentido histórico da ação educativa. Conjugam-se, portanto, a concepção de mundo que transcende o imediatismo do presente, o conhecimento dos condicionantes sociais da educação, a ação dirigida à busca de alternativas concretas para a formação de professores e o trabalho educativo (SILVA, 2011, p. 29).

Os pressupostos da formação continuada podem favorecer a construção de um recurso pedagógico que atenda às diversas necessidades de desenvolvimento profissional, principalmente, da formação de sua identidade como trabalhador, uma vez que "[...] estar em formação implica um investimento pessoal, um trabalho livre e criativo sobre os percursos e os projetos próprios, com vista à construção de uma identidade, que também é uma identidade profissional". (NÓVOA, 2002, p. 38-39).

Em suma, a expressão formação continuada traduz a ideia de um processo de educação prolongado por toda vida com a conotação de ser uma ação planejada e direcionada para a mudança. Para sua articulação com o âmbito institucional, é

\footnotetext{
3. Tal abordagem constitui um paradigma inovador na educação, tendo, no Brasil, Paulo Freire como sua principal referência, preconizando uma pedagogia politicamente engajada e crítica.
} 
fundamental que a efetivação desse processo também aconteça in loco, mimetizando-se ao fazer contínuo do trabalho, a fim de refletir-se em uma verdadeira prática social que mobilize todas as possibilidades e os saberes profissionais (MARIN, 1995).

Nóvoa (1995) faz uma crítica à formação docente que costuma ignorar o desenvolvimento pessoal do professor, assim como a articulação com os projetos das escolas. Nesse sentido, pode-se inferir que os modelos comumente empregados para a formação dos profissionais em geral desconsideram tanto a dimensão particular dos sujeitos, quanto a possibilidade de transformação da própria instituição e do meio social no qual estão inseridos, caracterizando-se em ações isoladas e com caráter instrumental.

Segundo ele, em uma interpretação já adaptada ao contexto deste trabalho, que inclui diferentes categorias profissionais, o desenvolvimento profissional em sua plenitude deve considerar três dimensões estratégicas na constituição de um programa de formação: a) desenvolvimento pessoal, com foco na vida do sujeito; b) desenvolvimento profissional, com foco na profissão; c) desenvolvimento organizacional, com foco na instituição. Essas seriam as diretrizes centrais para o alcance de uma formação conciliatória entre o profissional enquanto indivíduo e como ser social.

Outra compreensão adaptada a todos os profissionais da educação pela ótica da formação continuada para os docentes remete aos eixos de desenvolvimento dos profissionais da educação apontados por Candau (1997). Para a autora é importante: a) prezar a escola como espaço primordial para as ações de formação continuada; b) valorizar os saberes experienciais dos profissionais da educação; c) considerar as diversas etapas do desenvolvimento dos profissionais da educação.

Logo, entende-se que é essencial à formação continuada contemplar as necessidades de desenvolvimento do seu quadro de pessoal, reunindo a diversidade das características e das formações dos profissionais da educação que compõem o ambiente educacional. Para tanto, a próxima seção discorre sobre o desenvolvimento de pessoas no setor público, em especial, desses profissionais.

\section{O DESENVOLVIMENTO DE PESSOAS NO SETOR PÚBLICO}

A visão tradicional da administração de pessoal, que considera os seres humanos como meros recursos organizacionais, limitada à alocação dos indivíduos e à gerência dos aspectos trabalhistas, demonstra-se ultrapassada. Considerar as pessoas como sujeitos influentes do ambiente organizacional demanda vislumbrar o desenvolvimento 
profissional como mecanismo primordial na consecução dos objetivos organizacionais. (CHIAVENATO, 2006).

O investimento na capacitação e na qualificação dos trabalhadores passou a ter maior significância e a receber maior investimento por parte das organizações. De acordo com Rechziegel e Vanalle (2000), esse novo modelo de gestão de pessoas valoriza outros princípios, como o auto desenvolvimento, impulsionando os próprios indivíduos a agregarem competências, foco nos resultados, nas relações interpessoais e na motivação, sendo papel da gestão a mediação entre a organização e o colaborador.

$\mathrm{Na}$ esteira das organizações privadas, o setor público passou a adotar políticas para o desenvolvimento de pessoal num passado recente. De forma mais lenta e gradual, o setor público incorporou essas concepções, porém com maior necessidade de adaptações, tendo em vista a natureza das diferentes esferas organizacionais.

Acredita-se que o direcionamento de esforços na capacitação e na profissionalização de servidores públicos reverte-se em maior qualidade dos serviços prestados à sociedade. Ricupero (1994) enfatiza que a profissionalização do servidor público é condição sine qua non ao seu desenvolvimento, uma vez que sua ausência ou deficiência pode comprometer a concretização de projetos de interesse público.

Considerando que nesse trabalho não se pretende enfocar servidores públicos de diferentes esferas e que não seria possível abordar as inúmeras políticas utilizadas em estados e municípios, comentam-se as previsões sobre a matéria no âmbito federal. Conforme o histórico da administração pública brasileira é possível perceber que o desenvolvimento de pessoal está diretamente associado às reformas administrativas (ANDRADE, 2021).

Apesar de iniciativas anteriores, efetivamente, a legislação brasileira regulamenta a capacitação dos servidores na Constituição Federal (BRASIL, 1988), no Art. 39 e determina que o Estado mantenha escolas de governo ${ }^{4}$ para a formação e o aperfeiçoamento dos servidores públicos, as quais são coordenadas pela Escola Nacional de Administração Pública (ENAP) ${ }^{5}$. A ENAP é a instituição responsável pela formação e qualificação de servidores públicos em diferentes esferas do setor público.

Em 1998, foi lançada a primeira Política Nacional de Capacitação dos Servidores Públicos Federais, por meio do Decreto n² 2.794 (BRASIL, 1998). Entre seus objetivos, estava a melhoria da eficiência do serviço público e da qualidade dos serviços prestados

\footnotetext{
${ }^{4}$ Cita-se no Portal do Servidor do Governo Federal que há atualmente 16 instituições que integram o Sistema de Escolas de Governo da União.

${ }^{5}$ Para saber mais sobre a ENAP, há informações disponíveis no site: https://enap.gov.br/pt/.
} 
ao cidadão; a valorização do servidor público por meio de sua capacitação permanente; a divulgação e o controle de resultados das ações de capacitação com a respectiva racionalização e efetividade dos gastos (BRASIL, 1998).

O Decreto $n^{\circ} 5.707$ (BRASIL, 2006), embora revogado, é considerado um marco a respeito do desenvolvimento de servidores públicos ao estabelecer a Política Nacional de Desenvolvimento de Pessoal (PNDP). Com finalidades semelhantes aos da política lançada em 1998, a PNDP inova, ao adotar o modelo de competências pela aquisição de conhecimento, atribuindo diretrizes para o desenvolvimento de pessoal da administração pública federal direta, autárquica e fundacional.

Recentemente, houve uma atualização da referida PNDP com a publicação do Decreto nº 9.991 (BRASIL, 2019a), para o qual competência corresponde ao conjunto de conhecimentos, habilidades e condutas necessárias ao exercício do cargo ou da função. Manteve-se a prescrição de promover o desenvolvimento dos servidores públicos fundamentado nas competências requeridas para a excelência, na atuação dos órgãos e das entidades da administração pública federal direta, autárquica e fundacional. Ademais, estabelece maior ênfase na racionalização e na efetividade dos gastos, além de exigir uma detalhada divulgação no planejamento e, principalmente, na execução das ações de capacitação.

No que tange aos profissionais da educação da rede federal de ensino, cita-se: o artigo 67, inciso II, da LDB (BRASIL, 1996), a Lei $\mathrm{n}^{\circ} 13.005$ (BRASIL, 2014b) que aprova o Plano Nacional de Educação (PNE), o Decreto de n 8.752 (BRASIL, 2016a) que abarca a Política Nacional de Formação dos Profissionais da Educação Básica e a Resolução CNE/CP n² (BRASIL, 2019b) que define as Diretrizes Curriculares Nacionais para a Formação Inicial de Professores para a Educação Básica e institui a Base Nacional Comum para a Formação Inicial de Professores da Educação Básica (BNC - Formação).

Especificamente quanto à formação dos profissionais técnico-administrativos em educação, a Lei n 11.091 (BRASIL, 2005) estrutura o Plano de Carreira dos Cargos Técnico-Administrativos em Educação (PCCTAE), no âmbito das Instituições Federais de Ensino vinculadas ao Ministério da Educação e estabelece princípios e garantias de acesso a um programa de formação. O Decreto $n^{\circ} 5.825$ (BRASIL, 2006) estabelece as diretrizes para a elaboração do Plano de Desenvolvimento dos Integrantes do PCCTAE a ser instituído em cada IFE. Ambos incluem os profissionais técnicos tanto do Ensino Superior, quanto da RFEPCT. Ainda há a Portaria $n^{\circ} 15$ (BRASIL, 2016b) que trata exclusivamente do Plano de Formação Continuada dos Servidores da Rede Federal de Educação Profissional, Científica e Tecnológica (PLAFOR), neste, incluídos os docentes. 


\section{O Quadro 1, a seguir, elenca as legislações e os documentos oficiais referidos} neste trabalho, situando no tempo as medidas adotadas pelo poder público para a promoção do desenvolvimento de pessoas, em especial no que tange à formação dos profissionais da educação.

\section{Quadro 1: Resumo da legislação e documentos oficiais pertinentes ao tema da formação continuada dos profissionais da educação atuantes no setor público}

\begin{tabular}{|c|c|}
\hline $\begin{array}{l}\text { Constituição Federal } \\
\text { Constituição da República } \\
\text { Federativa do Brasil de } 1988 .\end{array}$ & Artigo 39. \\
\hline $\begin{array}{l}\text { Lei } n^{\circ} 9.394 \text {, de } 20 \text { de } \\
\text { dezembro de } 1996 .\end{array}$ & Estabelece as diretrizes e bases da educação nacional. \\
\hline $\begin{array}{l}\text { Decreto } n^{\circ} 2.794 \text {, de } 1^{\circ} \text { de } \\
\text { outubro de } 1998 \\
\text { (Revogado pelo Decreto } n^{\circ} \\
5.707 / 2006 \text { ). }\end{array}$ & $\begin{array}{l}\text { Institui a Política Nacional de Capacitação dos Servidores para a } \\
\text { Administração Pública Federal direta, autárquica e fundacional, e dá outras } \\
\text { providências. }\end{array}$ \\
\hline $\begin{array}{l}\text { Lei } n^{\circ} 11.091 \text {, de } 12 \text { de } \\
\text { agosto de } 2005 \text { (alterada } \\
\text { pela Lei } n^{\circ} 12.772 \text {, de } 28 \text { de } \\
\text { dezembro de } 2012 \text { ). }\end{array}$ & $\begin{array}{l}\text { Dispõe sobre a estruturação do Plano de Carreira dos Cargos Técnico- } \\
\text { Administrativos em Educação, no âmbito das Instituições Federais de } \\
\text { Ensino vinculadas ao Ministério da Educação, e dá outras providências. }\end{array}$ \\
\hline $\begin{array}{l}\text { Decreto } n^{\circ} 5.707 \text {, de } 23 \text { de } \\
\text { fevereiro de } 2006 \\
\text { (Revogado pelo Decreto } n^{\circ} \\
9.991 \text {, de 2019). }\end{array}$ & $\begin{array}{l}\text { Institui a Política e as Diretrizes para o Desenvolvimento de Pessoal da } \\
\text { administração pública federal direta, autárquica e fundacional, e } \\
\text { regulamenta dispositivos da Lei } n^{\circ} 8.112 \text {, de } 11 \text { de dezembro de } 1990 \text {. }\end{array}$ \\
\hline $\begin{array}{l}\text { Lei } n^{\circ} 12.014 \text {, de } 6 \text { de agosto } \\
\text { de } 2009 .\end{array}$ & $\begin{array}{l}\text { Altera o art. } 61 \text { da Lei } n^{\circ} 9.394 \text {, de } 20 \text { de dezembro de } 1996 \text {, com a } \\
\text { finalidade de discriminar as categorias de trabalhadores que se devem } \\
\text { considerar profissionais da educação. }\end{array}$ \\
\hline $\begin{array}{l}\text { Conferência Nacional de } \\
\text { Educação - CONAE } 2010\end{array}$ & $\begin{array}{l}\text { Documento-final: Construindo o sistema nacional articulado de educação: } \\
\text { o Plano Nacional de Educação, diretrizes e estratégias de ação. }\end{array}$ \\
\hline $\begin{array}{l}\text { Conferência Nacional de } \\
\text { Educação - CONAE } 2014\end{array}$ & Documento-final \\
\hline $\begin{array}{l}\text { Lei } n^{0} 13.005 \text {, de } 25 \text { de junho } \\
\text { de } 2014 .\end{array}$ & Aprova o Plano Nacional de Educação - PNE e dá outras providências \\
\hline $\begin{array}{l}\text { Decreto de } n^{\circ} 8.752 \text {, de } 9 \text { de } \\
\text { maio de } 2016 .\end{array}$ & $\begin{array}{l}\text { Dispõe sobre a Política Nacional de Formação dos Profissionais da } \\
\text { Educação Básica }\end{array}$ \\
\hline $\begin{array}{l}\text { Portaria } \mathrm{n}^{\circ} 15,11 \text { de maio de } \\
2016 .\end{array}$ & $\begin{array}{l}\text { Institui o Plano de Formação Continuada dos Servidores da Rede Federal } \\
\text { de Educação Profissional, Científica e Tecnológica - PLAFOR, e outras } \\
\text { providências. }\end{array}$ \\
\hline $\begin{array}{l}\text { Lei } n^{\circ} 13.415 \text {, de } 16 \text { de } \\
\text { fevereiro de } 2017 \text {. }\end{array}$ & $\begin{array}{l}\text { Altera as Leis } n^{\circ} 9.394 \text {, de } 20 \text { de dezembro de } 1996 \text {, que estabelece as } \\
\text { diretrizes e bases da educação nacional, e } 11.494 \text {, de } 20 \text { de junho } 2007 \text {, } \\
\text { que regulamenta o Fundo de Manutenção e Desenvolvimento da } \\
\text { Educação Básica e de Valorização dos Profissionais da Educação, a } \\
\text { Consolidação das Leis do Trabalho - CLT, aprovada pelo Decreto-Lei } n^{\circ} \\
5.452 \text {, de } 1^{\circ} \text { de maio de } 1943 \text {, e o Decreto-Lei } n^{\circ} 236 \text {, de } 28 \text { de fevereiro } \\
\text { de } 1967 \text {; revoga a Lei } n^{\circ} 11.161 \text {, de } 5 \text { de agosto de } 2005 \text {; e institui a } \\
\text { Política de Fomento à Implementação de Escolas de Ensino Médio em } \\
\text { Tempo Integral. }\end{array}$ \\
\hline
\end{tabular}




\begin{tabular}{|l|l|}
\hline $\begin{array}{l}\text { Conferência Nacional de } \\
\text { Educação - CONAE 2018 }\end{array}$ & Documento Base - Relatório Final \\
\hline $\begin{array}{l}\text { Decreto } n^{\circ} \text { 9.991, de 28 de } \\
\text { agosto de } 2019 \text { (alterado } \\
\text { pelo Decreto } n^{\circ} \text { 10.506, de } \\
2020\end{array}$ & $\begin{array}{l}\text { Dispõe sobre a Política de Desenvolvimento de Pessoas da administração } \\
\text { pública federal direta, autárquica e fundacional, e regulamenta dispositivos } \\
\text { da Lei } n^{\circ} 8.112 \text {, de 11 de dezembro de 1990, quanto a licenças e } \\
\text { afastamentos para ações de desenvolvimento. }\end{array}$ \\
\hline $\begin{array}{l}\text { Resolução CNE/CP n 2, de } \\
20 \text { de dezembro de 2019. }\end{array}$ & $\begin{array}{l}\text { Define as Diretrizes Curriculares Nacionais para a Formação Inicial de } \\
\text { Professores para a Educação Básica e institui a Base Nacional Comum } \\
\text { para a Formação Inicial de Professores da Educação Básica (BNC- } \\
\text { Formação). }\end{array}$ \\
\hline
\end{tabular}

Fonte: elaborado pelas autoras, 2021.

Diante do exposto, entende-se a importância de inserção das ações de formação continuada e do desenvolvimento de pessoas como práticas de gestão de forma sistemática e permanente. Assim, a próxima seção discute o papel da gestão na institucionalização de uma formação continuada aos profissionais da educação do setor público.

4.1 O papel da gestão na institucionalização de uma formação continuada aos profissionais da educação do setor público

Em face dos pontos apresentados até aqui e do intuito de adotar a formação continuada como modelo para a promoção do desenvolvimento dos profissionais da educação em geral, atuantes no setor público, retomam-se aspectos da formação continuada a serem considerados pela gestão, bem como o papel do planejamento e da avaliação na implementação de políticas de desenvolvimento institucionais que tenham "[...] impacto sobre a qualidade dos processos educacionais" (LUCK, 2008, p. 25).

Entende-se que a formação continuada é um investimento educativo que, para Libâneo (2008), reflete uma gestão que valoriza o desenvolvimento pessoal, a qualificação profissional e a competência técnica de seus profissionais e, além disso, acrescenta-se que se distingue enquanto um projeto de escola. Destarte, compreende-se a formação continuada como um processo educativo interativo e dinâmico, capaz de promover o desenvolvimento pessoal, profissional e organizacional (LIBÂNEO, 2008). E, complementa-se, uma formação política que permita a consciência da realidade social, a busca da emancipação e da formação enquanto cidadão.

Outrossim, a formação continuada ideal aos profissionais da educação necessita partir das relações concretas em que os sujeitos estão inseridos, propondo-se à reflexão sobre a práxis e a sua permanente articulação com o planejamento e o desenvolvimento 
institucionais. Os momentos de avaliação constituem oportunidades para a promoção do desenvolvimento profissional, uma vez que possibilitam a promoção da reflexão acerca das práticas concretas, contrapondo-as aos ideais almejados.

Sabe-se que inúmeros instrumentos de gestão demandados ao setor público sofrem influência dos paradigmas da iniciativa privada e dos regulamentos orientadores. Porém, Veiga (1995) ressalta que os instrumentos formais de planejamento e avaliação não devem ficar circunscritos a meros preenchimentos de formulários e cumprimento de metas. A determinação de utilizar certos dispositivos serve de oportunidade para a reflexão e para avançar além do aspecto formal. Com efeito, os instrumentos de gestão e avaliação determinados aos órgãos públicos podem favorecer um olhar mais abrangente, ao delegar aos próprios órgãos o mapeamento e a definição de suas prioridades e competências a serem desenvolvidas, como potencial instrumento de participação e exercício da democracia.

Uma das formas possíveis de construção de uma formação continuada institucionalizada é por meio do Plano de Gestão ou do Plano de Desenvolvimento Institucional (PDI), instrumentos obrigatórios para os órgãos públicos. Destaca-se a importância do papel do gestor em uma instituição pública, uma vez que a ação administrativa "ocupa o espaço-tempo" entre as decisões políticas e a implementação delas para o processo formativo, o que transforma a administração num ato pedagógico (VEIGA, 1995).

Seja qual for o documento utilizado em determinada instituição, "[...] é fundamental que os membros da instituição se sintam identificados com as informações, políticas, princípios, crenças, valores e projeções de futuro apresentados no documento." (LOPE; COSTA, 2014, p. 2). As mesma autoras pontuam que a identidade institucional está expressa no seu PDI, pois nele podem ser reconhecidos os elementos que constituem as crenças centrais e particulares de cada instituição e afirmam:

[...] a elaboração de um Plano de Desenvolvimento Institucional, constitui-se em um momento específico e marcante no percurso trilhado por uma instituição, pois oportuniza à mesma refletir sobre seu passado, presente e futuro, descobrindo seus pontos fortes e fracos e identificando suas ameaças e oportunidades (LOPE; COSTA, 2014, p. 12).

Refletindo-se sobre a obrigatoriedade legal de trabalhar o desenvolvimento de pessoas na área pública por meio de competências entende-se que, ao serem definidas, essas competências necessitam de conexão com o planejamento institucional. $\mathrm{Na}$ literatura, encontram-se inúmeras referências ao tema da gestão por competências. 
Conforme Ramos (2001), não se pode comparar a concepção de qualificação com a de competência, já que elas não são sinônimas. A qualificação é compreendida como uma relação social, com dimensões conceituais, sociais e experimentais. Por sua vez, o conceito de competência valoriza a dimensão experimental em detrimento das demais, o que supõe destacar os saberes tácitos e sociais, relegando os saberes formais. Em sua lógica está presente um rompimento com os códigos de contratação do trabalho estabelecidos social e coletivamente e a introdução de normas que, ainda que pactuadas coletivamente, têm aplicação individual. Revela-se assim, a ascendência da dimensão psicológica sobre a sociológica e consolida-se a tendência de uma profissionalização liberal, baseada na adaptabilidade individual às mudanças socioeconômicas e aos ditames do mercado.

Opta-se por uma posição técnica e política na escolha do modelo conceitual, frente ao qual compete à gestão adesão e compreensão de qual formação do trabalhador estará priorizando. Tal posição é resultado também de um processo de reflexão e planejamento e considera-se que este, no nível estratégico mais elevado da instituição, será o modelo de gestão que proporcionará ou não a participação de toda a organização (LOPE; COSTA, 2014). Desse modo, se o planejamento for elaborado de forma participativa, os objetivos mapeados a partir dele estarão mais próximos de serem reflexo das reais necessidades dos profissionais e, possivelmente, estarão de acordo com os eixos de desenvolvimento dos profissionais da educação, recomendados por Candau (1997).

Ainda, almeja-se a formação integral para o desenvolvimento de um servidor público crítico e reflexivo, apropriado de seus processos de trabalho e estimulado à construção coletiva de soluções para as questões institucionais. Justifica-se este ponto de vista, já que o espírito crítico é capaz de promover transformações culturais, sendo preciso atentar para a "[...] constituição de espaços institucionais integradores, capazes de proporcionar trocas transformadoras de experiências, saberes e fazeres" (FERNANDES, 2018, p. 57). Numa perspectiva de formação a partir da gestão compartilhada e participativa, os profissionais sentem-se motivados a (re)construir conhecimentos e saberes advindos do trabalho, considerando tanto suas experiências individuais, quanto as coletivas dos demais envolvidos no processo educativo (SERPA, 2020).

Para a aplicação de tais pressupostos às formações dos profissionais da educação do setor público é preciso que a reflexão sobre os objetivos a serem alcançados se estendam da instância de planejamento da formação às instâncias diretivas. Os desafios estão colocados quanto aos objetivos da formação de servidores e seu constante diálogo 
com a gestão, frente às contradições inerentes ao mundo do trabalho em seus embates com a exploração mercadológica da força de trabalho, cuja lógica expande-se às relações de trabalho em diferentes contextos sociais.

\section{CONSIDERAÇÕES FINAIS}

A formação continuada dos servidores da educação, prevista em instrumentos legais com vistas à qualificação na área, implica a valorização do desenvolvimento pessoal e profissional, bem como necessita considerar as experiências de vida dos profissionais, enquanto sujeitos ativos do processo educativo. Enfrenta-se, porém, inúmeros desafios para tal desenvolvimento: descontinuidades, capacitações reducionistas, mecanismos de gestão pseudo-democráticos, entre outros.

Contudo, é mister encontrar aliados à promoção das mudanças e ao cuidado com as pessoas formando redes de sustentação da qualificação almejada e da promoção humana e social presentes em suas bases. Nesse contexto, destaca-se o compromisso ético-político, pressupondo-se uma concepção do humano que se produz na inter-relação social e na transformação da natureza a partir do trabalho, sendo este, princípio educativo de toda formação a ser desenvolvida. Assim, as ações formativas necessitam contemplar a troca entre os pares, a coletividade, a valorização do seu trabalho e as experiências da ordem da subjetividade do trabalhador, constituindo-se possibilidade de reflexão a partir da práxis, transformando e promovendo sentido às atividades desenvolvidas.

No âmbito das IFEs, observa-se na realidade vivenciada pelas autoras, alguns pressupostos para os quais a opção por uma formação humana integral dos servidores pode contribuir para superá-los. Cita-se a percepção de que há um distanciamento do seu papel educativo por parte do servidor técnico decorrente da natureza de suas atividades administrativas. Entretanto, compreende-se por profissional da educação todos que atuam como mediadores da aprendizagem, seja atuando na atividade fim, seja nas atividades meio, devendo-se reafirmar o papel educativo do TAE.

De outro modo, a identificação do docente enquanto profissional da educação parece transcender a dimensão profissional para a constituição de sua personalidade enquanto sujeito social. Em contrapartida, o viés do serviço público está visivelmente mais arraigado nos técnicos, uma vez que associa muito mais o seu trabalho de natureza burocrática ao serviço público. Para os professores, a conexão entre a docência e as 
obrigações do serviço público situa-se preponderantemente no compromisso com a sociedade.

Tais controvérsias abrem a possibilidade de promover mudanças em alguns paradigmas da administração pública, tanto na realidade interna das instituições quanto no contexto externo, nos âmbitos sociais. Diante disso, entende-se que identidade e cultura organizacional relacionam-se com a coletividade, que é parte de um processo histórico e social. Nesse sentido, cada instituição vivencia sua própria realidade, que é única, de acordo com os sujeitos que a integram e com o processo histórico de sua constituição.

A valorização do trabalho e o sentido que cada sujeito atribui ao seu fazer sofre direta influência desses mecanismos sociais. A auto estima enquanto trabalhador e a sua identificação com o valor social a ele atribuído decorrem de uma formação indissociável entre as funções intelectuais e instrumentais aplicadas ao contexto de seu trabalho e a dinamicidade do real. A formação humana e integral do servidor envolve a dimensão política e produtiva, preparando-o para futuras funções como gestor, aliando conhecimento científico e técnico, consciente de seus direitos e deveres, da sua responsabilidade enquanto agente de transformação social.

Compreende-se que o desenvolvimento de pessoas por meio da formação continuada no serviço público, ao promover metodologias participativas, é um dos instrumentos de gestão e planejamento que possibilita a promoção da integralidade do ser humano. Este caminho pode apresentar-se como conciliatório, como ponto de partida para os objetivos de promoção da participação e de um projeto de sociedade que inclua, no mundo do trabalho, relações mais solidárias.

Por fim, parece que, mesmo diante da lógica privada imposta aos órgãos públicos, é possível identificar mecanismos que a gestão pode utilizar para incluir os membros da instituição. Um ciclo virtuoso pode ser engendrado a partir de sucessivas gestões que favoreçam a participação dos profissionais e estimulem as ações de formação. Desse modo, concedendo voz e vez a cada ciclo de planejamento, a cultura de uma gestão participativa e eficiente pode tornar-se, também, parte da identidade do servidor e da instituição.

Ressalta-se, ainda, a importância do seguimento de estudos acerca da formação continuada dos profissionais da educação no setor público e dos resultados deste investimento na qualidade da educação promovida. Outrossim, também como seus efeitos sobre a subjetividade dos trabalhadores, tais como a qualidade de vida, satisfação 
com as atividades desenvolvidas, redução de adoecimentos e afastamentos por motivo de saúde, cotidianos no sistema educativo atual, dentre outros.

\section{REFERÊNCIAS}

ABREU, K. Modelo de validação da aprendizagem informal visando a qualificação de servidores de organizações públicas. 2017. 47f. Dissertação (Mestrado em

Tecnologias, Gestão e Sustentabilidade). Universidade Estadual do Oeste do Paraná, Foz do Iguaçu, 2017. Disponível em:

http://tede.unioeste.br/bitstream/tede/3860/5/Katia_de_Abreu_2017.pdf. Acesso em: 30 abr. 2021.

ALVARADO-PRADA, L. E.; FREITAS, T. C., FREITAS, C. A. Formação continuada de professores: alguns conceitos, interesses, necessidades e propostas. Revista Diálogo Educacional, Curitiba, v. 10, n. 30, p. 367-387, maio/ago. 2010.

ANDIFES - Associação Nacional dos Dirigentes das Instituições Federais de Ensino Superior. Universidades Federais: patrimônio da sociedade brasileira. Disponível em: https://www.andifes.org.br/?page_id=261. Acesso em: 30 abr. 2021.

ANDRADE, L. M. Educação e Profissionalização no Serviço Público: a experiência da UFRGS com a implementação da Política Nacional de Desenvolvimento de Pessoal (2006-2018). 2021. 236f. Dissertação (Mestrado em Educação), Universidade Federal do Rio Grande do Sul. Porto Alegre, 2021.

ANDRÉ, M. E. D. A. Formação de professores: a constituição de um campo de estudos. Educação, Porto Alegre, v. 33, n. 3, p. 174-181, set./dez. 2010.

ASSIS GUERRA, E. L. A. Manual de pesquisa qualitativa. Grupo Nima Educação: Belo Horizonte, 2014.

BARDIN, L. Análise de conteúdo. Lisboa: Edições 70, 2004.

BRASIL. Constituição da República Federativa do Brasil de 1988. Disponível em: http://www.planalto.gov.br/ccivil_03/constituicao/constituicao.htm. Acesso em: 07 ago. 2020.

BRASIL. Lei $\mathrm{n}^{\circ}$ 9.394, de 20 de dezembro de 1996. Estabelece as diretrizes e bases da educação nacional. Disponível em: http://www.planalto.gov.br/ccivil_03/leis/19394.htm. Acesso em: 06 ago. 2020. 
BRASIL. Decreto $n^{\circ}$ 2.794, de $1^{\circ}$ de outubro de 1998. Institui a Política Nacional de Capacitação dos Servidores para a Administração Pública Federal direta, autárquica e fundacional, e dá outras providências. Disponível em:

http://www.planalto.gov.br/ccivil_03/decreto/D2794.htm. Acesso em: 13 mar. 2020.

BRASIL. Lei no 11.091, de 12 de agosto de 2005 (alterada pela Lei $n^{\circ} 12.772$, de 28 de dezembro de 2012). Dispõe sobre a estruturação do Plano de Carreira dos Cargos Técnico-Administrativos em Educação, no âmbito das Instituições Federais de Ensino vinculadas ao Ministério da Educação, e dá outras providências. Disponível em: http://www.planalto.gov.br/ccivil_03/_ato2004-2006/2005/lei//11091.htm. Acesso em: 07 ago. 2020.

BRASIL. Decreto 5.707, de 23 de fevereiro de 2006. Institui a Política e as Diretrizes para o Desenvolvimento de Pessoal da administração pública federal direta, autárquica e fundacional, e regulamenta dispositivos da Lei no 8.112, de 11 de dezembro de 1990. Disponível em:

http://www.planalto.gov.br/ccivil_03/_Ato20042006/2006/Decreto/D5707.htm. Acesso em: 13 mar. 2020.

BRASIL. Lei $\mathbf{n}^{\circ}$ 12.014, de 6 de agosto de 2009. Altera o art. 61 da Lei $n^{0}$ 9.394, de 20 de dezembro de 1996, com a finalidade de discriminar as categorias de trabalhadores que se devem considerar profissionais da educação. Disponível em: http://www.planalto.gov.br/ccivil_03/_Ato2007-2010/2009/Lei/L12014.htm\#art1. Acesso em: 07 ago. 2020.

BRASIL. Construindo o sistema nacional articulado de educação: o Plano Nacional de Educação, diretrizes e estratégias de ação. Documento final da CONAE 2010. Brasília, DF: MEC, 2010. Disponível em:

http://conae.mec.gov.br/images/stories/pdf/pdf/documetos/documento_final.pdf. Acesso em: 06 ago. 2020.

BRASIL. Relatório Final. Brasília, DF: MEC, 2014a. Disponível em:

http://confinteabrasilmais6.mec.gov.br/images/documentos/documento_final_CONAE_201 4.pdf. Acesso em: 10 ago. 2020.

BRASIL. Lei $\mathbf{n}^{\circ} \mathbf{1 3 . 0 0 5}$, de 25 de junho de 2014. Aprova o Plano Nacional de Educação PNE e dá outras providências. 2014b. Disponível em:

<https://www2.camara.leg.br/legin/fed/lei/2014/lei-13005-25-junho-2014-778970-

publicacaooriginal-144468-pl.html>. Acesso em: 07 set. 2020.

BRASIL. Decreto de $\mathbf{n}^{\circ}$ 8.752, de 9 de maio de 2016. Dispõe sobre a Política Nacional de Formação dos Profissionais da Educação Básica. 2016a. Disponível em: http://www.planalto.gov.br/ccivil_03/_ato2015-2018/2016/decreto/d8752.htm. Disponível em: 07 set. 2020 
BRASIL. Portaria No 15, 11 de maio de 2016. Institui o Plano de Formação Continuada dos Servidores da Rede Federal de Educação Profissional, Científica e Tecnológica PLAFOR, e outras providências. 2016b. Disponível em:

http://portal.mec.gov.br/docman/40991-portaria-15-2016-setec-12maio-pdf/file. Acesso em: 03 ago. 2020.

BRASIL. Lei $n^{\circ}$ 13.415, de 16 de fevereiro de 2017. Altera as Leis $n^{\circ} 9.394$, de 20 de dezembro de 1996, que estabelece as diretrizes e bases da educação nacional, e 11.494, de 20 de junho 2007, que regulamenta o Fundo de Manutenção e Desenvolvimento da Educação Básica e de Valorização dos Profissionais da Educação, a Consolidação das Leis do Trabalho - CLT, aprovada pelo Decreto-Lei $n^{\circ} 5.452$, de $1^{\circ}$ de maio de 1943 , e o Decreto-Lei $n^{\circ} 236$, de 28 de fevereiro de 1967; revoga a Lei $n^{\circ} 11.161$, de 5 de agosto de 2005; e institui a Política de Fomento à Implementação de Escolas de Ensino Médio em Tempo Integral. 2017. Disponível em: http://www.planalto.gov.br/ccivil_03/_ato20152018/2017/lei//13415.htm. Acesso em: 10 ago. 2020.

BRASIL. Documento Base: Relatório Final. Brasília, DF: MEC, 2018. Disponível em: http://fne.mec.gov.br/images/Documento_Base_-_Relatorio_Final_da_CONAE_2018.pdf. Acesso em: 24 ago. 2020.

BRASIL. Decreto n 9.991, de 28 de agosto de 2019. Dispõe sobre a Política de Desenvolvimento de Pessoas da administração pública federal direta, autárquica e fundacional, e regulamenta dispositivos da Lei $n^{\circ} 8.112$, de 11 de dezembro de 1990, quanto a licenças e afastamentos para ações de desenvolvimento. 2019a. Disponível em: http://www.planalto.gov.br/ccivil_03/_ato2019-2022/2019/decreto/D9991.htm. Acesso em: 15 out. 2019.

BRASIL. Resolução CNE/CP n 2, de 20 de dezembro de 2019. Define as Diretrizes Curriculares Nacionais para a Formação Inicial de Professores para a Educação Básica e institui a Base Nacional Comum para a Formação Inicial de Professores da Educação Básica (BNC-Formação). 2019b. Disponível em:

http://portal.mec.gov.br/docman/dezembro-2019-pdf/135951-rcp002-19/file. Acesso em: 07 set. 2020.

BRASIL. Instituições da Rede Federal. 2021. Disponível em: http://portal.mec.gov.br/rede-federal-inicial/instituicoes. Acesso em: 30 abr. 2021.

CANDAU, V. M. Formação continuada de professores: tendências atuais. In: CANDAU, V. M. (Org.). Magistério: construção cotidiana. Petrópolis: Vozes, 1997. p.51-68.

CASTAMAN, A. S.; VIEIRA, M. M. M. Formação Continuada de Professores na Educação Profissional. REGAE - Revista de Gestão e Avaliação Educacional, Santa Maria, v. 2, n. 3, p. 7-15, jan./jun. 2013. Disponível em:

https://periodicos.ufsm.br/regae/article/view/10037. Acesso em: 30 abr. 2021. 
CASTAMAN, A. S.; RODRIGUES, R. A. Considerações sobre gestão democrática e participativa na Educação Profissional e Tecnológica. Educitec. Manaus, v. 04, n. 08, Edição Especial, p. 494-507, nov. 2018. Disponível em:

https://sistemascmc.ifam.edu.br/educitec/index.php/educitec/article/view/389. Acesso em: 30 abr. 2021.

CHIAVENATO, I. Administração geral e pública. Rio de Janeiro: Elsevier, 2006.

CURY, A. Organização e métodos: uma visão holística. 7. ed. São Paulo: Atlas, 2000.

FERNANDES, M. W. A Formação continuada dos Profissionais da Educação na Educação Profissional e Tecnológica: o lugar ocupado pelo social. In: CASTAMAN, A. S.; VIEIRA, J. A. (Orgs.). Gestão da Educação Profissional e Tecnológica: elementos para reflexão. 1. Ed. Curitiba: CRV, 2018, v. 1, p. 49-58.

GATTI, B. A.; BARRETO, E. S. S.; ANDRÉ, M. E. D. A. Políticas docentes no Brasil: um estado da arte. Brasília: UNESCO, 2011.

GIL, A. C. Como elaborar projetos de pesquisa. 4. ed. São Paulo: Atlas, 2007.

GIL, A. C. Métodos e técnicas de pesquisa social. 6 ed. São Paulo: Atlas, 2008.

LIBANIO, J. B. A arte de formar-se. São Paulo: Loyola, 2001.

LIB NEO, J. C. Democratização da Escola Pública. São Paulo: Loyola, 1990.

LIBÂNEO, J. C. Princípios e características da gestão escolar participativa. In: LIBÂNEO, J. C. Organização e gestão da escola: teoria e prática. 5. ed. Goiânia: MF Livros, 2008, p. 135-146.

LIBÂNEO, J. C.; OLIVEIRA, J. F.; TOSCHI, M. S. Educação escolar: políticas, estrutura e organização. São Paulo: Cortez, 2017.

LOPE, J. R. F. S.; COSTA, P. L. S. Identidade institucional e Gestão Participativa nos Institutos Federais: possibilidades de fortalecimento e ressignificação a partir do PDI. In: XIV COLÓQUIO INTERNACIONAL DE GESTÃO UNIVERSITÁRIA - CIGU. 2014, Florianópolis. Anais..., Florianópolis, 2014

LUCK, H. Liderança em gestão escolar. Rio de janeiro: Vozes, 2008. 
MARCELO GARCÍA, C. Formação de professores para uma mudança educativa. Porto: Porto editora, 1999.

MARCELO GARCÍA, C. A formação de professores: novas perspectivas baseadas na investigação sobre o pensamento do professor. In: NÓVOA, A. (Org.). Os professores e a sua formação. Lisboa: Dom Quixote, 1995. p. 51-76.

MARIN, A. J. Educação continuada: introdução a uma análise de termos e concepções. São Paulo: Papirus, 1995.

MENEZES, E. T.; SANTOS, T. H. Verbete IFES (Instituições Federais de Ensino Superior). Dicionário Interativo da Educação Brasileira - Educabrasil. São Paulo: Midiamix, 2001. Disponível em: https://www.educabrasil.com.br/ifes-instituicoes-federaisde-ensino-superior/. Acesso em: 07 ago. 2020.

MINAYO, M. C. S. (org.). Pesquisa social: teoria, método e criatividade. Rio de Janeiro: Vozes, 2007.

NÓVOA, A. Formação de professores e profissão docente. In: NÓVOA, António. (Org.). Os professores e a sua formação. 2. ed. Lisboa: Dom Quixote, 1995. p.15-33.

NÓVOA, A. Formação de professores e trabalho pedagógico. Lisboa: Educa, 2002.

OLIVEIRA, A. M. A influência do clima organizacional na motivação dos servidores da Fundação Alfredo da Matta. 2008. 78f. (Dissertação de Mestrado). Programa de PósGraduação em Administração Pública, Fundação Getúlio Vargas, Rio de Janeiro - RJ, 2008. Disponível em: http://bibliotecadigital.fgv.br/dspace/handle/10438/3468. Acesso em: 30 abr. 2021.

PIMENTA, S. G. Professor: formação, identidade e trabalho docente. In: PIMENTA, S. G. Saberes pedagógicos e atividade docente. 2. ed. São Paulo: Cortez, 2000. p.15-35.

RAMOS, M. N. A pedagogia das competências: autonomia ou adaptação? São Paulo: Cortez, 2001, 320p.

RECHZIEGEL, W.; VANALLE, R. M. Novas práticas de recursos humanos e a competitividade. In: ENCONTRO NACIONAL DE ENGENHARIA DE PRODUÇÃO, 20, 2000, São Paulo. Anais...São Paulo, 2000.

RICUPERO, R. Profissionalização do servidor público: requisito para o desenvolvimento. Revista do Serviço Público, Brasília, v. 45, n. 2, p. 149-153, 1994. Disponível em: https://revista.enap.gov.br/index.php/RSP/article/view/804. Acesso em: 30 abr. 2021. 
RIVAS, N. P. P. et al. Formação continuada de profissionais da educação: a busca de integração entre gestão e currículo no cotidiano escolar. Paidéia, Ribeirão Preto, n.12-13, p. 135-157, Ago. 1997. Disponível em:

https://www.scielo.br/scielo.php?script=sci_arttext\&pid=S0103-863X1997000100010. Acesso em: 30 abr. 2021.

ROSSI, F.; HUNGER, D. As etapas da carreira docente e o processo de formação continuada de professores de Educação Física. Revista brasileira de Educação Física e Esporte, São Paulo, v. 26, n. 2, p. 323-338, abr./jun. 2012. Disponível em: https://www.scielo.br/scielo.php?pid=S180755092012000200014\&script=sci_abstract\&tlng=pt. Acesso em: 30 abr. 2021.

SERPA, I. A. et al. A gestão escolar e a formação de professores: interlocuções e possibilidades. Debates em Educação, Maceió, v. 12, n. 28, p. 543-553, Set./Dez. 2020. Disponível em: https://www.seer.ufal.br/index.php/debateseducacao/article/view/9396. Acesso em: 15 set. 2020.

SILVA, K. A. C. P. C. A formação de professores na perspectiva crítico-emancipadora. Revista Linhas Críticas, Brasília, DF, v. 17. n. 32. p. 13-31, jan./abr. 2011. Disponível: https://periodicos.unb.br/index.php/linhascriticas/article/view/3668. Acesso em: 30 abr. 2021.

SILVEIRA, F. R.; CASTAMAN, A. S. Formação continuada de profissionais da educação: problematizações na educação profissional e tecnológica. Revista de Estudos e Pesquisas sobre Ensino Tecnológico, Manaus, v. 6, p. 1-15, jan./dez., 2020. Disponível em: https://sistemascmc.ifam.edu.br/educitec/index.php/educitec/article/view/934. Acesso em: 30 abr. 2021.

VEIGA, I. P. A. (Org) Projeto Político Pedagógico da Escola: uma construção possível. Campinas: Papirus, 1995.

VERGARA, S. C. Métodos de Pesquisa em Administração. São Paulo: Atlas, 2005

VIEIRA, J. A.; VIEIRA, M. M. M.; BELUCAR, M. C. A. Formação continuada de professores da educação profissional: particularidades e ações necessárias. Revista Eletrônica Científica Ensino Interdisciplinar, Mossoró, v. 4, n. 10, p. 100-117, 2018. Disponível em: http://periodicos.uern.br/index.php/RECEl/article/view/2518/1535. Acesso em: 30 abr. 2021. 